\title{
Working
}

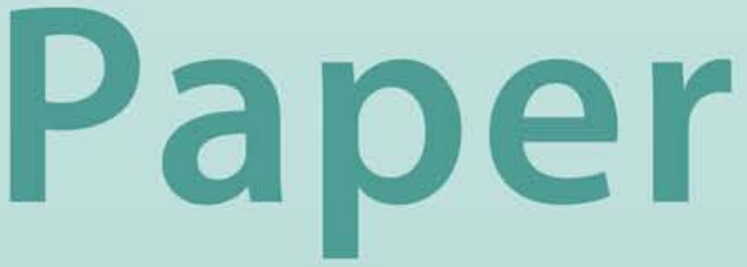


Exchange Rate Pass-Through to Domestic Prices: Does the Inflationary Environment Matter?

Ehsan U. Choudhri and Dalia S. Hakura 


\title{
IMF Working Paper
}

IMF Institute

\section{Exchange Rate Pass-Through to Domestic Prices: Does the Inflationary Environment Matter?}

\author{
Prepared by Ehsan U. Choudhri and Dalia S. Hakura ${ }^{1}$ \\ Authorized for distribution by Samir El-Khouri
}

December 2001

\begin{tabular}{l} 
Abstract \\
$\begin{array}{l}\text { The views expressed in this Working Paper are those of the author(s) and do not necessarily } \\
\text { represent those of the IMF or IMF policy. Working Papers describe research in progress by the } \\
\text { author(s) and are published to elicit comments and to further debate. }\end{array}$ \\
\hline
\end{tabular}

The paper tests a hypothesis suggested by Taylor (2000) that a low inflationary environment leads to a low exchange rate pass-through to domestic prices. To test this hypothesis, the paper derives a pass-through relation based on new open economy macroeconomic models. A large database that includes 1979-2000 data for 71 countries is used to estimate this relation. There is strong evidence of a positive and significant association between the passthrough and the average inflation rate across countries and periods. The inflation rate, moreover, dominates other macroeconomic variables in explaining cross-regime differences in the pass-through.

JEL Classification Numbers:F41, E31, E52

Keywords: Pass-through, inflation, exchange rate

Author's E-Mail Address: dhakura@imf.org

${ }^{1}$ Ehsan Choudhri is Professor of Economics at Carleton University and Visiting Scholar at the IMF Institute. Dalia Hakura is Economist in the IMF Institute. The authors would like to thank Samir El-Khouri, Hamid Faruqee, Andrew Feltenstein, Mohsin Khan, Douglas Laxton and the participants of a Workshop at the IMF Research Department and a Seminar at the IMF Institute for helpful comments and suggestions. 
I. Introduction 3

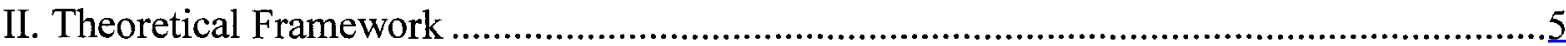

A. Price Setting and the Exchange Rate Pass-Through ................................................5

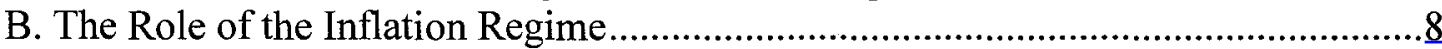

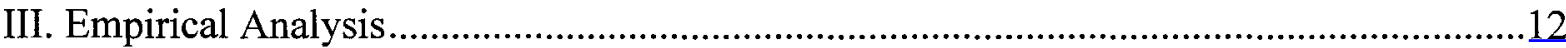

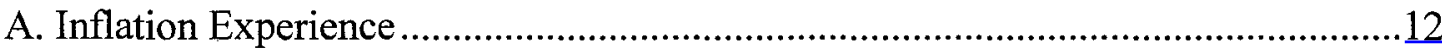

B. Estimation of the Pass-Through .......................................................................13

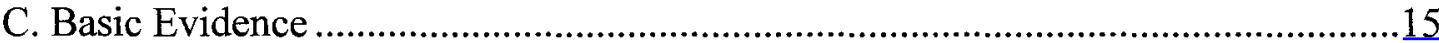

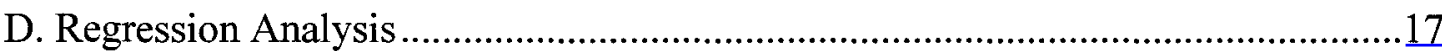

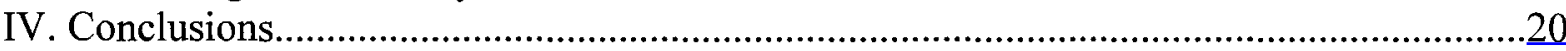

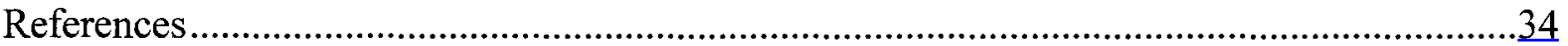

Text Tables

1. Selected Characteristics of Inflation: Sample Countries ................................................21

2. Estimates of Exchange Rate Pass-Through: Countries With A Single Inflation Regime ..22

3. Estimates of Exchange Rate Pass-Through: Countries With Two Inflation Regimes..........23

4. Correlation of Exchange Rate Pass-Through With the Average Inflation Rate: Regressions in First Differences ............................................................................24

5. Correlation of Exchange Rate Pass-Through With the Average Inflation Rate:

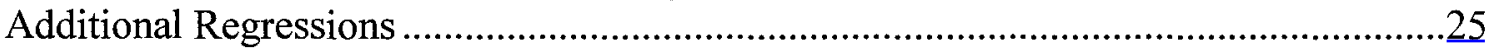

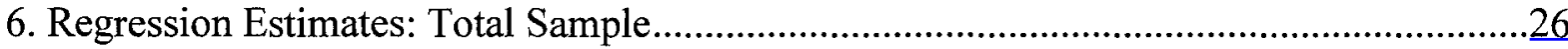

7. Regression Estimates: Selected Samples ....................................................................27

8. Regression Estimates: Weighted Least Sqaures ............................................................28

Figures

1. Countries With Shifts in Inflation Regimes..................................................................29

2. Association Between Average Inflation and Exchange Rate Pass-Through .........................30

Appendices

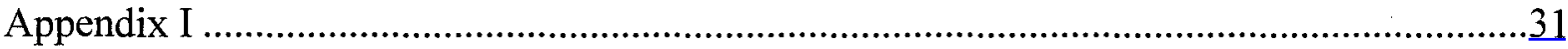

A. Complete Asset Markets ...................................................................................

B. Incomplete Asset Markets ..................................................................................

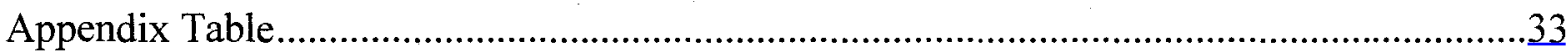




\section{INTRODUCTION}

The degree to which changes in the exchange rate pass-through to prices is an important issue in debates about appropriate monetary and exchange rate policies. A low exchange rate pass-through is thought to provide greater freedom for pursuing an independent monetary policy and to make it easier to implement inflation targeting. There is no consensus, however, on the conditions that lead to a low pass-through. Traditional literature has been concerned with the exchange rate pass-through to import prices and has stressed the role of market power and price discrimination in international markets (pricing to market). ${ }^{2}$ This literature suggests that the import price pass-through (at the sectoral or aggregate level) is essentially determined by microeconomic factors (e.g., demand elasticities, market structure) that are exogenous to monetary policy. ${ }^{3}$

An alternative view has been put forth by John Taylor (2000), who argues that the recently-observed declines in the pass-through to aggregate prices are the result of a low inflation environment. Taylor explains the link between inflation and pass-through in terms of a model of firm behavior based on staggered price setting and monopolistic competition. As firms set prices for several periods in advance, their prices respond more to cost increases (due to exchange rate depreciation or other sources) if cost changes are perceived to be more persistent. Regimes with higher inflation tend to have more persistent costs. ${ }^{4} \mathrm{~A}$ high inflation environment would thus tend to increase the exchange rate pass-through. In this view, the pass-through depends on the policy regime: a credible low inflation regime will automatically achieve a low pass-through.

Recently, there has been a growing interest in examining the relationship of the exchange rate pass-through with monetary policy behavior and the inflationary environment. A number of recent studies find some empirical support for the relationship but the evidence is not conclusive. Campa and Goldberg (2001) provide evidence on the pass-through to import prices based on data for OECD countries. They find that although higher inflation and exchange rate volatility are positively associated with higher import price pass-through, microeconomic factors related to the composition of imports play a much more important role in determining the pass-through. The import price pass-through reflects the price behavior of foreign firms and this behavior may not be strongly related to the home inflationary environment. Thus evidence

${ }^{2}$ See, for example, Goldberg and Knetter (1997) for a survey of this literature.

${ }^{3}$ A related strand in the literature emphasizes the role of local versus producer currency pricing in the determination of the exchange rate pass-through. The pricing method chosen by foreign firms is generally regarded as exogenous to domestic monetary policy. See, however, Devereux and Engel (2001) who endogenize this choice and relate it to monetary stability.

${ }^{4}$ Taylor (2000) provides evidence showing that the disinflation in the US has been associated with a reduction in the persistence of inflation. 
on the pass-through to domestic prices (e.g., CPI) would provide a more appropriate test of the Taylor view. Gagnon and Thrig (2001) explore the relationship between CPI pass-through and inflation stabilization for eleven industrial countries. ${ }^{5}$ They find that the pass-through generally declined in the 1990's and the change in the pass-through is significantly related to the variability of inflation. They also explore but do not find a systematic relation between the passthrough and the monetary policy behavior.

The paper extends the literature relating pass-through to inflation in two directions. First, the paper's empirical analysis uses a large database that comprises of 1979-2000 data for 71 countries and includes developing as well as industrial countries. ${ }^{6}$ As the inflationary experience varies much more among developing countries than among industrial countries, our database is especially suitable for exploring how inflation affects the pass-though. The theoretical link between inflation and the pass-through has not been adequately discussed in terms of a fullyspecified macroeconomic model. A second contribution of the paper is to derive such a link using a general equilibrium framework based on new open-economy macroeconomic models. The theoretical framework also suggests a general form of the pass-through relation that can be implemented empirically.

Our theoretical framework incorporates staggered pricing, but simplifies the dynamics of the exchange and wage rates in response to monetary shocks. We assume that regimes which are able to maintain low inflation rates on average are also more successful in stabilizing the inflation rate. This assumption is formalized as a monetary rule whereby a regime that targets a lower inflation rate, responds more strongly to deviations from the target. The dependence of CPI pass-through on the inflationary environment arises essentially because the pass-through reflects the expected effect of monetary shocks on current and future costs. A low inflation regime lowers the pass-through by weakening the expected future effect of the shocks (via its reaction to price deviations from the target path). Low inflation economies could also be subject to less variable monetary shocks. The lower variability of monetary shocks would decrease the information content of the exchange rates in predicting monetary shocks and this effect suggests another reason for the pass-through to be smaller under a low inflation regime.

The paper estimates the pass-through to CPI (over short as well as long periods) using an empirical model suggested by the theory. Most of the countries in our database appear to experience a single inflation regime during the sample period. We find strong evidence of a

\footnotetext{
${ }^{5}$ McCarthy (2000) uses a VAR model to estimate the pass-through to CPI for a number of countries. He shows that the pass-through tends to be larger for countries with higher exchange rate persistence but does not relate the pass-through to the inflationary experience of the countries.

${ }^{6}$ Our database is similar to that used in the Goldfajn and Werlang (2000) study of the exchange rate pass-through. Their study, however, is concerned with other determinants of the passthrough and does not focus on the influence of the inflationary environment.
} 
positive and significant association between the pass-through and the average inflation rate across these countries. Further evidence in support of a robust link between inflation and the pass-through is provided by a small number of countries that experienced a dramatic shift in the inflation environment. This shift was accompanied by a marked change in the pass-through for all of these countries. We also explore the influence of other macroeconomic variables on the pass-through and find that the average inflation rate dominates these variables in explaining cross-regime variation in the pass-through.

Section II discusses the theoretical framework and derives the relation between the CPI pass-through and the inflation regime. Section III discusses the methodology and presents the results of the empirical analysis. Conclusions are offered in section IV.

\section{THEORETICAL FRAMEWORK}

This section discusses the theoretical framework underlying the pass-through relation examined in this paper. The framework is based on the new open-economy macroeconomic models and incorporates imperfect competition and price inertia. We consider a variation of these models, which treats final consumer goods as non-traded goods and imports as intermediate inputs into the production of consumer goods. ${ }^{7}$ We also assume a production structure suggested by Basu (1995), in which each variety can be used both as a final good and an intermediate input. Price inertia is assumed to arise from staggered price adjustment. We assume a Stiglitz-Dixit aggregator function for differentiated consumer goods and intermediate inputs. Furthermore, we assume that prices are set in producer's currency. These assumptions abstract from the role of pricing to market and local-currency pricing but allow us to simplify the analysis of the effect of the inflationary environment on the exchange rate pass-through. ${ }^{8}$

\section{A. Price Setting and the Exchange Rate Pass-Through}

We consider a model of two countries, home and foreign. Households in each country consume a continuum of differentiated varieties produced domestically. The home sub-utility function for the differentiated consumption good is

$$
U_{t}=\left[\int_{0}^{n} U_{t}(i)^{(\sigma-1) / \sigma} d i\right]^{\sigma /(\sigma-1)}
$$

\footnotetext{
${ }^{7}$ McCallum and Nelson (1999) use such a variant, for example. This variation underscores the dependence of the CPI on the price behavior of home firms. The pass-through relation that we estimate, however, would not be affected much if the CPI also includes imported goods.

${ }^{8}$ See Bergin and Feenstra (2001) for a model with staggered pricing that incorporates pricing to market (based on a translog aggregator function) and local currency pricing. They use this model to explain persistence in real exchange rates.
} 
where $n$ represents the range of domestically-produced varieties. The price index for the consumer good is given by the unit expenditure function for $U_{t}$ as

$$
P_{t}=\left[\int_{0}^{n} P_{t}(i)^{1-\sigma} d i\right]^{1 /(1-\sigma)}
$$

Each variety is produced with the following Cobb-Douglas production function:

$$
Y_{t}=A Z_{t}^{\alpha} L_{t}{ }^{\mathrm{l}-\alpha} \text {, }
$$

where $Y_{t}$ is output, $Z_{t}$ is a composite intermediate input and $L_{t}$ is the amount of labor. The composite intermediate is obtained by aggregating domestic and imported varieties via the following aggregator function (which is the same as the one used for $U_{t}$ ):

$$
Z_{t}=\left[\int_{0}^{n+n^{*}} Z_{t}(i)^{(\sigma-1) / \sigma} d i\right]^{\sigma /(\sigma-1)}
$$

where $n^{*}$ represents the range for foreign varieties (we later allow for the possibility that not all foreign varieties are imported). Letting $\widetilde{P}_{t}$ denote the unit cost of $Z_{t}$ and $W_{t}$ the wage rate, we can derive each variety's marginal cost of production from (3) as

$$
C_{t}=\widetilde{P}_{t}^{\alpha} W_{t}^{1-\alpha}
$$

Using an asterisk to denote foreign variables, we assume that relations analogous to (1)(5) hold for the foreign economy. The home variety is supplied to final and intermediate demand at home as well as intermediate demand abroad. Let $\widetilde{P}_{t}^{*}$ represent the unit cost of $Z_{t}^{*}$ in foreign currency and $S_{t}$ denote the exchange rate (expressed as the price of foreign currency). The demand for a home variety can then be expressed as

$$
D_{t}(i)=\delta_{t} P_{t}(i)^{-\sigma}
$$

where $\delta_{t}=U_{t} / P_{t}^{\sigma}+Z_{t} / \widetilde{P}_{t}^{\sigma}+Z_{t}^{*} /\left(S_{t} \widetilde{P}_{t}^{*}\right)^{\sigma}$.

Assume that the price of each variety is fixed for $T$ periods. Let $X_{t}$ denote the fixed price set in $t$. (Thus, for a variety $j$ whose price is set in $t, P_{t+\tau}(j)=X_{t}$, for $\tau=0, \ldots, T-1$ ). The value of $X_{t}$ is chosen to maximize the expected discounted value of profits over $T$ periods and can be derived using (6) as 


$$
X_{t}=E_{t}^{x} \frac{\sigma \sum_{\tau=0}^{T-1} \beta^{\tau} \delta_{t+\tau} C_{t+\tau}}{(\sigma-1) \sum_{\tau=0}^{T-1} \beta^{\tau} \delta_{t+\tau}},
$$

where $\beta$ is the discount factor and $E_{t}^{x}$ denotes the expectation operator conditional on information available for setting $X_{t}{ }^{9}$ We assume that firms observe the contemporaneous value of the exchange rate (the information set at $t$ includes $s_{t}$ ). All other variables are observed with a one-period lag. We also assume a uniform overlap between prices so that prices of $n / T$ home varieties (and $n^{*} / T$ foreign varieties) are set in each period. Then using (2), we can restate the price of the home consumer good as

$$
P_{t}=\left[(n / T) \sum_{\tau=0}^{T-1} X_{t-\tau}^{1-\sigma}\right]^{[/(1-\sigma)} .
$$

Approximate versions of the key price-setting relations can be obtained by linearizing these relations around steady-state values. A bar over a variable is used to indicate steady-state values and lower-case letters are employed to denote proportional deviations of variables from their steady-state values (e.g., $\left.x_{t}=\left(X_{t}-\bar{X}_{t}\right) / \bar{X}_{t}\right)$. Relations (7) and (8) can be linearized as

$$
\begin{aligned}
& x_{t}=\frac{1}{T} \sum_{\tau=0}^{T-1} E_{t}^{x} c_{t+\tau}, \\
& p_{t}=\frac{1}{T} \sum_{t=0}^{T-1} x_{t-\tau},
\end{aligned}
$$

where the linear expressions are simplified by assuming that $\beta \approx 1$ and the steady-state values are constant over time. ${ }^{10}$ In view of (4), $\widetilde{P}_{t}=\left[n P_{t}^{1-\sigma}+n^{*}\left(S_{t} P_{t}^{*}\right)^{1-\sigma}\right]^{1 /(1-\sigma)}$, where $P_{t}^{*}$ is the aggregate price of foreign varieties in foreign currency $\left(S_{t} P_{t}^{*}\right.$ is thus the aggregate homecurrency price of imported intermediates). Using this condition and (3), (5) can be linearized as

${ }^{9}$ Firms solve the problem: $\max E_{t} \sum_{\tau=0}^{T-1} \beta^{\tau}\left[X_{t}-C_{t+\tau}\right] \delta_{t+\tau} X_{t}^{-\sigma}$. The first order condition for this problem is used to obtain (7).

${ }^{10}$ An appealing feature of the simplified expressions is that they are similar to the ones used in the standard staggered-price models. These expressions, however, can be easily modified to allow $\beta$ to be greater than one, and nominal variables to grow at a constant rate in the steady state (as is assumed below). Such modifications would not alter (9) and (10) significantly, especially if $T$ is small (our theoretical analysis below focuses on the case of $T=2$ ). 


$$
c_{t}=\alpha \theta p_{t}+\alpha(1-\theta)\left(s_{t}+p_{t}^{*}\right)+(1-\alpha) w_{t},
$$

where $\theta=n \bar{P}^{1-\sigma} /\left[n \bar{P}^{1-\sigma}+n^{*}\left(\overline{S P}^{*}\right)^{1-\sigma}\right]$ represents the steady-state share of home intermediates in production.

Relations (9)-(11) represent the basic channels that transmit the effect of exchange rate changes to consumer prices. A change in the exchange rate has a direct impact on costs via (11). Given staggered price adjustment process (10), however, the exchange rate change will initially pass-through to only a fraction of goods whose prices are being reset. In resetting prices according to (9), firms will take into account the influence of the exchange rate on the expected values of future costs. Expectations thus play an important role in determining the exchange rate pass-through.

To solve for the expected costs $\left(E_{t}^{x} c_{t+\tau}\right)$, we need to add relations that determine $w_{t}$ and $s_{t}$. We consider below a simple model of household preferences and asset markets, which relates these variables to monetary shocks and simplifies their dynamics. This model provides a simple framework for examining the link between the inflationary environment and the exchange rate pass-through.

\section{B. The Role of the Inflation Regime}

We first briefly outline household behavior. Households allocate a fixed amount of time between work and leisure and their utility depends on the differentiated good (via the sub-utility function), real money balances and labor supply. The representative household in the home country is assumed to maximize the following simple objective function:

$$
E_{t} \sum_{t=0}^{\infty} \beta^{t}\left[\log U_{t}+\log \left(M_{t} / P_{t}\right)-L_{t}\right]
$$

Foreign households maximize an analogous function. We also assume, that households in both countries have access to a complete set of state contingent assets (we later consider departures from this assumption). As Bergin and Feenstra (2001) show, household optimization under these assumptions implies the following linear approximations:

$$
\begin{aligned}
& m_{t}=u_{t}+p_{t}=w_{t}, \\
& s_{t}+p_{t}^{*}-p_{t}=u_{t}-u_{t}^{*} .
\end{aligned}
$$

The first equality in (12) is based on the stable solution to a difference equation based on the linearized forms of the Euler and money-demand conditions while the second equality represents the linear version of the labor-supply condition. Equation (13) gives the linearized form of the risk-sharing condition whereby the ratio of home and foreign utilities is proportional to the real exchange rate as implied by the assumption of complete asset markets. 
In this simple setup, inflation behavior depends on the monetary policy regime. For our purposes, essential characteristics of monetary regimes can be stated in terms of a pricetargeting rule. Assume for simplicity, that the regime targets $X_{t}$ and chooses a deterministic target path for this variable with a specified rate of growth (the target inflation rate). The steady state path of $X_{t}$ will coincide with its targeted path. In steady state, moreover, $P_{t}$ and $M_{t}$ will grow at the same rate as $X_{t}$. We consider the following simple linearized form of the rule:

$$
m_{t}=-\rho x_{t-1}+v_{t}
$$

where $v_{i}$ is a stochastic monetary shock with variance equal to $\sigma_{v}^{2}$ and $\rho(>0)$ is a parameter that measures the extent to which policy responds to deviations from the target. Our key assumption is that $\rho$ is inversely related to the target inflation rate: a low inflation regime makes a stronger effort to bring the prices back to the target path. This assumption provides a simple basis for establishing a positive link between the long-run inflation rate and the exchange rate pass-through. ${ }^{11}$ We also assume that the variability of monetary shocks (i.e., $\sigma_{v}^{2}$ ) is smaller in regimes with lower inflation targets. This secondary assumption provides a further reason for a positive relation between the inflation rate and the pass-through.

To illustrate the link between the inflationary environment and the exchange rate passthrough, we simplify certain features of the model. We focus on the case of a small home economy $\left(n^{*}\right.$ large relative to $n$ ) that exerts a negligible effect on foreign prices. However, to allow for a non-negligible share of home intermediates $(\theta)$, we now assume that only a fraction of foreign varieties is imported because of home bias. ${ }^{12}$ To isolate the effects of the home monetary regime, assume that the foreign monetary regime introduces no monetary shocks so that $m_{t}^{*}=p_{t}^{*}=0$. Under these assumptions, (12), its foreign counterpart and (13) imply that

$$
w_{t}=m_{t}=s_{t}
$$

Consider the simple case where prices are set for two periods $(T=2)$ and $v_{t}$ is white noise. The model comprising of (9)-(11) and (14)-(15) can be solved by the method of undetermined coefficients to obtain a relation of the following form:

${ }^{11}$ As discussed below, our model implies that an increase in $\rho$ leads to a decrease in both the persistence and the variance of $p$. Thus our assumption (that $\rho$ is negatively related to the target rate) accounts for the stylized fact that the variability of inflation is smaller in regimes with lower inflation rates as well as the Taylor view that low inflation regimes tend to have low inflation persistence.

${ }^{12}$ Let $\zeta$ represent the fraction. Then $\zeta n^{*}$ will replace $n^{*}$ - in (4) and (11). 


$$
p_{t}=\mu_{1} p_{t-1}+\mu_{2}\left(s_{t}+s_{t-1}\right) / 2
$$

where $\mu_{1}$ and $\mu_{2}$ depend on $\rho, \alpha$ and $\theta$. The short-run exchange rate pass-through (i.e., the impact of a one unit increase in $s_{t}$ on $p_{t}$ ) equals $\mu_{2} / 2$. The pass-though over a longer period would also depend on $\mu_{1}$, which represents the degree of persistence in $\mathrm{p}$. As shown in the Appendix (by numerical methods), both $\mu_{1}$ and $\mu_{2}$ decrease in $\rho .{ }^{13}$ Thus a larger value of $\rho$ (associated with low inflation regimes) would decrease the exchange rate pass-through both in the short and the long run. ${ }^{14}$ This result can be explained intuitively as follows. The exchange rate pass-through reflects the effect of monetary shocks on current and future costs. A larger value of $\rho$ (representing a stronger monetary policy response) reduces the effect of the shocks on future costs and hence lowers the pass-through.

The analysis so far is based on the special assumption of complete asset markets. This assumption can be relaxed in a simple way by modifying (13) as

$$
s_{t}+p_{t}^{*}-p_{t}=u_{t}-u_{t}^{*}+\eta_{t}
$$

where $\eta_{t}$ is an error term that represents departures from complete asset markets and can be thought of as a shock to the real exchange rate. Using (12), its foreign counterpart and (17), and recalling that $m_{t}^{*}=0$, we can restate (15) as

$$
w_{t}=m_{t}=s_{t}-\eta_{t}
$$

Thus, in the presence of incomplete markets, the exchange rate is an imperfect indicator of the money stock and would provide a noisy signal for monetary shocks. The solution of the modified model [consisting of (9)-(11), (14) and (18)] is also discussed in the Appendix. Assuming that $\eta_{t}$ is white noise with variance equal to $\sigma_{\eta}^{2}$ and is uncorrelated with $v_{t}$, the appendix shows that the model implies a relation of the same form as (16). The values of $\mu_{1}$

${ }^{13}$ The Appendix also shows that $\mu_{1}$ increases and $\mu_{2}$ decreases in $\alpha \theta$. The effect on $\mu_{1}$ arises because a larger share of intermediate inputs in costs (i.e., an increase in $\alpha$ ) increases pricelevel persistence. The effect on $\mu_{2}$, on the other hand, reflects the influence of a decrease in the share of imported varieties in intermediate inputs (i.e., a decrease in $1-\theta$ ) on the pass-through in the short run.

${ }^{14}$ Note that the pass-through to import prices equals 1 (the aggregate import price can be linearized as $s_{t}+p_{t}^{*}$ ) and does not depend on the home inflationary environment. A limitation of our model is that it abstracts from pricing to market and local currency pricing, and thus does not provide an explanation of an incomplete import price pass-through. 
and $\mu_{2}$, however, now also depend on $\lambda \equiv \sigma_{\eta}^{2} /\left(\sigma_{\eta}^{2}+\sigma_{v}^{2}\right)$. Both $\mu_{1}$ and $\mu_{2}$ decrease in $\lambda$ as well as in $\rho$. Since $\sigma_{v}^{2}$ is assumed to be smaller in countries with lower inflation, this result suggests another reason why the exchange rate pass-through would be less in these countries. The intuition for this result is simply that the lower variability of monetary shocks decreases the information content of the exchange rate in predicting monetary shocks. ${ }^{15}$

Our analysis above has related the pass-through to the long-run inflation rate, which is viewed as the key indicator of the monetary policy regime. Other macroeconomic indicators, such as measures of the exchange rate or inflation variability have also been suggested in the literature. Our model, however, does not imply a clear relation between the pass-through and the variance of $p$ or $s$, as shown in the Appendix. Under incomplete asset markets, for example, the variance of $p$ decreases in $\rho$ and increases in $\sigma_{v}^{2}$, but the sign of the partial effect of $\sigma_{\eta}^{2}$ on this variance is ambiguous. In the case of the variance of $s$, even the sign of the partial effect of $\rho$ is ambiguous. Thus it is not obvious that a regime with a high variance of $p$ or $s$ would necessarily have higher values of $\mu_{1}$ and $\mu_{2}$. The variance measures may still be empirically useful indicators of monetary policy regimes (instead of or in addition to the inflation rate) and this issue is explored in the empirical analysis below.

Although the simple pass-through relation (16) is useful in illustrating how the inflationary environment affects the exchange rate pass-through, it is derived from a special version of the model, which assumes that prices are fixed for only two periods, shocks are white noise and foreign prices equal their steady state paths $\left(p_{t}^{*}=0\right)$. For our empirical analysis, however, we consider a general version of the model that relaxes these assumptions. The general version suggests a pass-through relation of the following form:

$$
p_{t}=\pi_{1}(L) p_{t-1}+\pi_{2}(L) s_{t}+\pi_{3}(L) p_{t-1}^{*}
$$

where $\pi_{1}(L), \pi_{2}(L)$ and $\pi_{3}(L)$ are lag polynomials. The order of the lag polynomials would depend not only on $T$ (the number of periods for which prices are fixed) but also on the stochastic processes for the exogenous variable $p_{t}^{*}$ and the shocks, $v_{t}$ and $\eta_{t}$. Our empirical analysis will allow the data for an inflation regime to determine the length of each lag polynomial. Since the exchange rate is not a perfect measure of the money stock in the case of incomplete markets, lagged values of the money stock could be used to predict future monetary shocks in this case and would, in general, also enter (19). We thus also consider an augmented version of (19), which includes lagged values of $m_{t}$. Shocks to the real exchange rate could also

${ }^{15}$ Another potential reason for low inflation to reduce the pass-through is that prices could be changed less frequently (i.e., fixed for a longer period) under a low inflationary environment. Although this effect is not fully explored in the paper, it can be shown, as a simple example, that the pass-through is less for $T=2$ as compared to $T=1$. 
include a non-stationary component that represents the effect of changes in net foreign assets arising from temporary shocks under incomplete markets. ${ }^{16}$ As discussed further below, the introduction of a non-stationary error term in (19) would require estimation of this relation in first differences.

Finally, note that we have used a very simple targeting rule to distinguish inflation regimes. In reality, monetary policy regimes differ in much more complex ways. Our simple rule is intended to capture key attributes of the inflationary environment even if the policy regime does not explicitly target inflation. ${ }^{17}$ Our analysis assumes, however, that the policy regime is stable (i.e., follows a particular monetary rule). Thus it may not be appropriate (as discussed below) for hyperinflation situations.

\section{EMPIRICAL ANALYSIS}

This section describes the data and the methodology used to estimate the exchange rate pass-through and discusses the basic results on the association between inflation and the passthrough. We use a large sample that consists of time series data from 1979 to 2000 for 71 countries and includes economies from all major regions. ${ }^{18}$

\section{A. Inflation Experience}

Table 1 summarizes the behavior of quarterly CPI inflation (expressed as annual rates) for our sample countries. These countries exhibit a wide range of inflation experience. The mean rate of inflation varies from a low of 1.5 for Bahrain to a high of 124.4 for Brazil. There is also considerable cross-country variation in the range and the standard deviation of the inflation rate.

Countries with high inflation are more likely to experience major changes in their inflation environment. One possibility is that inflation could get out of control and lead to

${ }^{16}$ Lane and Milesi-Ferretti (2000) provide evidence on the effect of net foreign assets on the real exchange rate. Although our model abstracts from productivity shocks, the presence of such shocks could also cause the real exchange rate to be non-stationary for Balassa-Samuelson reasons.

${ }^{17}$ Even if the regime targets monetary aggregates or the exchange rate, rule (14) could still provide a useful as if description of the extent to which the regime tolerates deviations from the long-run path of prices (consistent with the target path of the money stock or the exchange rate). Also note that more complex forms of the rule (e.g., targeting of $P_{t}$ instead of $X_{t}$ ) would be accommodated in our general version (19).

18 The data were obtained from the Information Notice System Database of the IMF, except where it is indicated otherwise. See Zanello and Desruelle (1997) for a complete description of the database. 
hyperinflation characterized by very high and accelerating inflation rates. Another possibility is that an inflation stabilization program is able to bring down inflation rates to low or moderate levels. To explore possible shifts in inflation regimes, we examined the inflation behavior of countries with mean inflation rate above $30 \%$. For a number of these countries, high inflation represented a chronic situation over the sample period. ${ }^{19}$ For eight countries, however, there is a clear indication of a switch in inflation regimes. These shifts are identified in Figure 1 (and Table 3). Five countries in this group - Argentina, Bolivia, Brazil, Nicaragua and Peru experienced hyperinflation for a certain period but were successful in stabilizing inflation and maintaining moderate rates afterwards. The remaining three countries did not undergo hyperinflation but did experience a significant change in their inflationary environment. Israel and Mexico implemented successful stabilization programs to reduce inflation from high to moderate levels. Romania, on the other hand, shifted from low to high inflation at the time of its transition to a market economy.

For the three countries that did not have hyperinflation episodes (Israel, Mexico and Romania), the time series data is simply divided into two periods and each period is treated as a distinct inflation regime. For Bolivia and Nicaragua, pre-stabilization periods are dominated by hyperinflation and are unlikely to constitute inflation regimes with stable expectations (as assumed by our pass-though model). Our empirical analysis thus focuses only on the regimes represented by post-stabilization periods for these two countries. The remaining three countries (Argentina, Brazil and Peru) experienced shorter bouts of hyperinflation (these periods are enclosed by the dotted and solid lines in Figure 1). For these countries, the entire prestabilization periods, or parts of these periods without the hyperinflation episodes, are viewed as separate regimes in our tests below.

\section{B. Estimation of the Pass-Through}

For each inflation regime, we consider the following log-linear relation based on (19):

$$
\log P_{t}=\gamma_{0}+\gamma_{1} t+\pi_{1}(L) \log P_{t-1}+\pi_{2}(L) \log S_{t}+\pi_{3}(L) \log P_{t-1}^{*}+\varepsilon_{t}
$$

where $P_{t}$ represents the home CPI, $S_{t}$ and $P_{t}^{*}$ are the effective nominal exchange rate and the foreign CPI, and $\varepsilon_{t}$ is the error term in quarter $t .^{20}$ The exchange rate pass-through to CPI over

${ }^{19}$ These countries include Ecuador, Sierra Leone, Turkey, Uruguay and Zambia. Although the inflation rate for these countries fluctuates considerably over the sample period, there is no clear indication of a switch in inflation regime.

${ }^{20}$ Log deviations are used to approximate proportional deviations around steady-state values (i.e., $\left.\log P_{t}-\log \bar{P}_{t} \approx\left(P_{t}-\bar{P}_{t}\right) / \bar{P}_{t}\right)$. Initial steady-state values (in $\operatorname{logs}$ ) are included in the constant term and a trend term is introduced to allow for possible trends in these values. As discussed in section 2, lagged values of $\log M_{t}$ could also enter (20). This variation is explored below. 
T periods can be defined as the accumulated partial effect of a one-unit increase in the log of nominal exchange rate in period $t$ on the $\log$ of CPI in period $t+T-1$ (i.e., the sum of dynamic multipliers: $\left.\sum_{\tau=0}^{T-1} \partial \log P_{t+\tau} / \partial \log S_{t}\right){ }^{21}$ The $T$ - period pass-through can be calculated from coefficient estimates of lag polynomials, $\pi_{1}(L)$ and $\pi_{2}(L){ }^{22}$

The inflation series used for each country is the seasonally adjusted CPI. Exchange rate changes for each country are calculated using the nominal trade-weighted effective exchange rates of domestic currency over foreign currency. A series for foreign $\mathrm{CPI}$ is extracted from the relative price index (RPI) reported by the INS. ${ }^{23}$ The INS monthly series are converted to quarterly series by taking simple averages of the monthly data over each quarter.

The appropriate form for estimating the pass-through relation depends on whether this relation is cointegrated or not. As discussed above, a non-stationary real exchange rate implies that the error term in the pass-through relation is non-stationary and the relation should be estimated in the first-difference form. The issue of whether the real exchange rate is stationary or has a unit root has not been settled despite a vast literature on testing the purchasing power parity. We also explore this issue for our sample. First, using time series data for individual countries, we find that Augmented Dickey-Fuller tests do not reject the null of a unit root for most countries. ${ }^{24}$ Time series in our sample cover a period of about two decades and tests based on such a short span of time have limited power. Panel data has been used to increase the power of the unit-root tests. Although this approach also raises problematic issues, we applied unit-root tests to panel data formed by combining the time series data for our sample countries. ${ }^{25} \mathrm{~A}$ test

${ }^{21}$ Note that this cumulative effect is the same as the effect of a permanent one unit increase in the log of the nominal exchange rate in $t$ on the log of the CPI in $t+T-1$. We focus on the effect of a permanent change in the nominal exchange rate because this variable tends to be non-stationary (and thus subject to permanent shocks)

${ }^{22}$ The dynamic multiplier $\partial \log P_{t+\tau} / \log S_{t}$ equals the coefficient of the $\tau$ 'th term in the lag polynomial $\varphi(L)=\left[1-\pi_{1}(L)\right]^{-1} \pi_{2}(L)$.

${ }^{23}$ The RPI is defined as the ratio of domestic CPI for a country to trade weighted averages of the CPI's of partner countries. The series for the foreign CPI is obtained from this series by subtracting the $\log$ of the domestic CPI from the log relative price index.

${ }^{24}$ The unit root null is not rejected for 64 out of 71 countries at the $5 \%$ level. The test includes a constant and a time trend (if significant). The criterion for choosing the number of lags (up to a maximum of 6 lags) was based on a general-to-specific procedure.

${ }^{25}$ The basic problem with panel methods is that they test the null hypothesis that all individual series have a unit root. The null hypothesis could be modified to allow some of the series to be 
due to Im, Pesaran and Shin (1997) did not reject the unit root null for the whole panel. ${ }^{26}$ In view of this evidence, the basic estimation in this section assumes that $\varepsilon_{t}$ has a unit root and estimates $(20)$ in the following first difference form:

$$
\Delta \log P_{t}=\gamma_{1}+\pi_{1}(L) \Delta \log P_{t-1}+\pi_{2}(L) \Delta \log S_{t}+\pi_{3}(L) \Delta \log P_{t-1}^{*}+\varepsilon_{t}^{\prime}
$$

Equation (21) is estimated separately for each inflation regime. However, to explore the sensitivity of our estimates to the assumption that the pass-through relation is not co-integrated, we later also examine estimates based on the level form of the pass-through relation (20).

\section{Basic Evidence}

To examine the exchange rate pass-through over the short, medium and long run, Tables 2 and 3 show estimates of the $T$-period pass-through for $T=1,2,4,20$. These estimates are based on (21) with the order of each lag polynomial determined by the Schwartz criterion. Table 2 provides the pass-through estimates for countries with a single inflation regime while Table 3 gives the estimates for those with two regimes. Table 2, classifies countries into three groups based on the average inflation rate (defined as the mean of $\Delta \log P_{t}$, expressed as an annual rate). Low, moderate and high inflation groups are defined as consisting of countries with average inflation rates less than 10 percent, between 10 and 30 percent and more than 30 percent, respectively. Most of the countries in this table (i.e., countries with single regimes) fall into the low and moderate inflation groups. Also note that while developing countries appear in all three inflation groups, all industrial countries are included in the low inflation group. The average exchange rate pass-through for each group rises as $T$ increases, as would be expected. Comparing the average pass-through across groups, the table indicates a positive relation between inflation and the pass-through. For each $T$, the average pass-through is the lowest for the low inflation group and the highest for the high inflation group.

Table 3 provides further evidence on the influence of inflation on the pass-through based on within-country comparisons of high and moderate inflation regimes for six countries. For

stationary. Tests based on such a modified hypothesis have been applied to samples with a small number of countries (e.g., Alan Taylor, 2000) but are computationally cumbersome for our sample, which contains a large number of countries.

${ }^{26}$ The probability level for the Im, Pesaran and Shin (1997) test (including a time trend) is 0.45. This procedure tests the unit root null against the alternative of heterogeneous roots across units. The unit root hypothesis, however, is rejected for our panel by the Levin and Lin (1993) test, which is based on a more restrictive alternative of homogeneous roots across units. For both tests, one country and the first four observations were dropped to form a balanced panel. These tests were implemented using GAUSS programs by Chiang and Kao (2001), NPT 1.2, and by Ouliaris and Phillips, COINT 2.0. 
Argentina, Brazil and Peru (which experienced hyperinflation episodes), two alternative definitions of high inflation regimes are used: one including and the other excluding the hyperinflation period. In all cases, the pass-through for the high inflation regime is greater than that for the moderate regime for each value of $\mathrm{T}$. The inter-regime difference in the passthrough is pronounced in most cases. As our model of the pass-through would predict, F-tests reject the null hypothesis that coefficients in the lag polynomials of the pass-through relation are the same between the two regimes. For Bolivia and Nicaragua (where the high inflation period is largely characterized by hyperinflation), the pass-through is estimated for only the moderate inflation period. These estimates are used in the cross-regime tests discussed below.

The cross-regime association between the average inflation rate and the exchange rate pass-through is illustrated in Figure 2 for the short $(T=1)$ as well as the medium $(T=4)$ run. Figures $2 \mathrm{a}$ and $2 \mathrm{~b}$ show the association across countries with single regimes. These countries tend to have low and moderate inflation rates and are bunched at the lower end of the inflation scale. Nevertheless, the figures indicates a clear positive relation between inflation and the passthrough. Figures $2 \mathrm{c}$ and $2 \mathrm{~d}$ show the relation between inflation and the pass-through across regimes for countries that experienced a regime shift. ${ }^{27}$ This sample represents a wider variation in inflation rates and suggests an even stronger relation than the single-regime sample.

Pearson and Spearman rank correlations between the average inflation rate and the $T$ period pass-through across regimes are shown in Table 4 for $T=1,2,4,20$. The correlation coefficients are computed for the total sample as well as for samples restricted to countries with either one or two inflation regimes. In all cases, the correlation coefficients are significant at the 5 percent level, using a one-tail test of positive correlation.

Calvo and Reinhart (2000) present evidence that the exchange rate pass-through tends to be larger in emerging economies as compared to developed countries. As emerging economies also tend to have higher inflation rates, this finding could reflect the effect of inflation on the pass-through. It is possible, on the other hand, that some other factors account for the passthrough difference between developed and developing countries and the correlations between inflation and pass-through are picking up the effect of these factors. This issue can be explored by examining the relation between inflation and the pass-through separately for each country group. As noted above, all industrial countries experienced low inflation during our sample period and there is very little dispersion of inflation rates among these countries. Inflation rates vary considerably, however, among developing countries (see Table 1), and Table 4 shows the correlations between inflation and pass-through for these countries. The association between the two variables is positive and significant for the total as well as the single-regime sample of developing countries. Also note that the group experiencing shifts in inflation regimes includes

27 The high-inflation periods for Argentina, Brazil and Peru in these figures refer to the longer periods that include hyperinflation. The relations based on the shorter high-inflation periods (excluding hyperinflation) would not be much different. 
only developing countries, and as already discussed above, there is a strong association between inflation and the pass-through for this group.

Table 5 examines the sensitivity of the results to certain variations in the specification of the pass-through relation. First, as the evidence on whether the pass-through relation is cointegrated or not is not conclusive, we also estimate this relation in the level form. The table shows that correlation coefficients between inflation and the pass-through based on the level regressions are significant in all cases except one (the Pearson coefficient for the $T=20$ passthrough is not significant in the case of countries with regime shifts). Next, we explore the possibility that the first-difference form of the pass-through relation includes the lagged values of money growth. Correlations between inflation and the pass-through based on these regressions are also shown in Table $5 .^{28}$ These correlations are significant in all cases. In contrast to the results for the level regressions, the first-difference regressions with money growth show that inflation is strongly correlated with the long-run pass-through for countries with two regimes. The pass-through relation could potentially include other variables such as the gap between actual and potential (or target) output. ${ }^{29}$ Data limitations, however, make it difficult to explore such a variation for our large sample of countries.

\section{Regression Analysis}

We next undertake regression analysis to further examine the effect of the average inflation rate on the pass-through and to explore the influence of other macroeconomic variables. We consider three additional variables, which represent measures of inflation variability, exchange rate volatility and the degree of openness (to imported goods). We estimate a regression of the following form:

$$
P T_{R}(T)=b_{0}+b_{1} I N F A_{R}+b_{2} I N F V_{R}+b_{3} E X R V_{R}+b_{4} O P E N_{R}+e_{R},
$$

where subscript $R$ indexes the inflation regime, $P T_{R}(T)$ is the estimated pass-through for $T$ periods, $I N F A_{R}$ is the average inflation rate, $I N F V_{R}$ is the variance of the inflation rate, $E X R V_{R}$ is the variance of the proportional exchange rate change (i.e., $\Delta \log S_{t}$, expressed as an annual

${ }^{28}$ The source of the data for money growth is the IMF's International Financial Statistics, line 34. The reported money series is seasonally adjusted. For countries where this data are not reported, the money series is estimated as the sum of currency in circulation and demand deposits, which is then seasonally adjusted.

${ }^{29}$ In terms of our theoretical model, this variable could be motivated by the assumption that the monetary policy rule also includes the output gap. 
rate), $O P E N_{R}$ is the import to GDP ratio, and $e_{R}$ is the error term. ${ }^{30}$ We initially estimate (22) by OLS, but later address the problem that the variance of $e_{R}$ may be different across regimes.

OLS estimates of (22) for the total sample are shown in Table 6 for $T=1$ and $T=20 .^{31}$ In this table, we also show estimates of simple regressions of $P T_{R}(T)$ on each explanatory variable separately. The simple regressions show that while the pass-through (in both the short and the long run) is not significantly affected by the import to GDP ratio, it is positively and significantly related to the average inflation rate and the inflation and exchange rate variances. As would be expected, the two variances are strongly correlated with the average inflation rate and with each other. ${ }^{32}$ The multicollinearity between these variables could potentially make it difficult to isolate the effect of these variables in regression (22). Estimates of (22) show, however, that the average inflation rate clearly dominates the other variables and is the only variable that exerts a significant and positive effect. Our estimates of (22) indicate that a $10 \%$ increase in the average inflation rate increases the short-run pass-through by about 0.05 and the long-run one by about 0.06 . It is interesting to note that recent studies based on the OECD data do not find the effect of the inflation rate on the pass-through to be as strong as in our analysis. ${ }^{33}$ This difference in results may be due to the fact that there is much more variation in the inflation rate across regimes in our sample than in the OECD sample.

To examine the sensitivity of our results to the data for different country groups, Table 7 estimates (22) for samples that consist of the one-regime, two-regime or developing countries. The effect of the average inflation rate differs across country groups, especially in the case of

${ }^{30}$ The data on the ratio of imports of goods and services to GDP are obtained from the World Bank's World Development Indicators.

31 The regression equation was also estimated for $\mathrm{T}=2$ and $\mathrm{T}=4$, but the results were similar and are not reported in the table.

32 The correlations between the four explanatory variables are as follows:

$\begin{array}{lrrrr} & \text { INFA } & \text { INFV } & \text { EXRV } & \text { OPEN } \\ \text { INFA } & 1 & 0.85 & 0.82 & -0.25 \\ \text { INFV } & & 1 & 0.96 & -0.27 \\ \text { EXRV } & & & 1 & -0.28 \\ \text { OPEN } & & & & 1\end{array}$

${ }^{33}$ Gagnon and Ihrig (2001), for example, find that the standard deviation of the inflation rate performs better the average inflation rate in explaining cross-regime variation in the passthrough. Campa and Goldberg (2001) show, moreover, that a measure of exchange rate volatility (similar to ours) is a significant determinant of the pass-through (to import prices) in regressions that include the average inflation rate. 
the long-run pass-through. In all cases, however, the inflation rate continues to exert a positive and significant effect on the pass-through. The effects of the inflation and exchange rate variances remain insignificant. We also explored the sensitivity of our results to alternative estimates of the pass-through based on the level regression (20) and on the first-difference regression (21) augmented by lagged money growth terms. These variations did not much effect our result that the average inflation rate is the key determinant of the pass-through.

The pass-through measure is subject to a regime-specific estimation error and the variance of this error could differ across regimes. One way to deal with this problem is to estimate (22) by weighted least squares (WLS), using the inverse of the (normalized) standard error of the pass-through estimate as weights. This weighting scheme is appealing as it gives less weight to more noisy estimates of the pass-through. One problem with this procedure, however, is that a few observations with exceptionally low standard errors of the estimate could distort the results by giving an unduly high weight to outliers. This problem can be avoided by excluding such outliers. A more general problem is that the procedure represents an overadjustment as the error in estimating the pass-through is only a part of the overall error $\left(e_{R}\right) .^{34}$ We estimate (22) by WLS, nevertheless, to examine whether WLS estimates (with an overadjustment) differ much from the OLS estimates (with no adjustment).

Table (8) presents WLS estimates of (22) for the total sample as well as the one-regime, two-regime and developing countries samples. The regression is estimated for $T=1$ and $T=20$, using the inverse of the standard error of the estimate for $P T_{R}(T)$ as the weight series in each case. $^{35}$ The regressions for the short-run pass-through exclude one outlier (Burkina Faso), where

${ }^{34}$ Let $e_{R}=e_{R}^{P}+e_{R}^{O}$, where $e_{R}^{P}$ is the error for the pass-through estimate and $e_{R}^{O}$ is the error from other sources. Assume that $e_{R}^{P}$ and $e_{R}^{O}$ are uncorrelated and the variance of $e_{R}^{O}$ is the same for all $R$. Let $\sigma_{P R}^{2}$ denote the regime-specific variance of $e_{R}^{P}$ and $\sigma_{O}^{2}$ the variance of $e_{R}^{O}$. Our WLS regressions use the weights, $\xi_{R}=\sigma_{P} / \sigma_{P R}$, where $\sigma_{P}$ is the average of $\sigma_{P R}$ across $R$. The appropriate weight for each observation, however, is the inverse of the standard deviation of $e_{R}$ normalized by its average. Denoting this weight by $\chi_{R}$, it can be shown that $\chi_{R}=\xi_{R}\left\{\left[1+\left(\sigma_{O}^{2} / \sigma_{P}^{2}\right)\right] /\left[1+\xi_{R}^{2}\left(\sigma_{O}^{2} / \sigma_{P}^{2}\right)\right]\right\}^{1 / 2}$. For a nonzero $\sigma_{O}^{2}, \chi_{R}<\xi_{R}\left(>\xi_{R}\right)$ if $\xi_{R}>1(<1)$. Thus the WLS regressions give too much (little) weight to observations with below-average (above-average) $\sigma_{P R}$.

${ }^{35}$ The standard error of the coefficient of $\Delta \log S_{t}$ from regression (21) is used to estimate the standard error of $P T_{R}(1)$. The standard error of $P T_{R}(20)$ is approximated by the standard error of the long-run pass-through, $\pi_{2}(1) /\left[1-\pi_{1}(1)\right]$. This standard error is derived from the standard errors and the covariance of $\pi_{1}(1)$ and $\pi_{2}(1)$, which are obtained from re-estimating (21) in the following transformed form:

$\Delta \log P_{t}=\gamma_{1}+\pi_{1}(1) \Delta \log P_{t-1}+\pi_{2}(1) \Delta \log S_{t}+\pi_{1}^{\prime}(L) \Delta^{2} \log P_{t-1}+\pi_{2}^{\prime}(L) \Delta^{2} \log S_{t}+\pi_{3}(L) \Delta \log P_{t-1}^{*}+\varepsilon_{t}^{\prime}$. 
the standard error of the $T=1$ pass-through is very low and much below that of other regimes. As in the case of OLS estimates, the effect of the average inflation rate on the pass-through is positive and significant in all regressions. Other variables, however, do not have a robust effect across different regressions. The effect of the inflation rate variance, for example, is significant and negative on the long-run pass-through for the total and developing country samples but insignificant for the one- and two-regime samples. The effect of this variable on the short-run pass-through, moreover, is insignificant for all samples.

\section{Conclusions}

The paper explores a model of the exchange rate pass-through, which emphasizes the role of price inertia and expectations. As prices are set for several periods in the model, the pass-through includes the expected effect of changes in the exchange rate on future costs and prices. The expected effect depends on the inflation regime. For high inflation regimes, the effect of monetary shocks tends to be more persistent and is likely to be reflected in exchange rate changes to a larger degree. For these reasons, the model implies the hypothesis that the exchange rate pass-through is larger in high inflation regimes.

This paper undertakes an extensive empirical analysis based on a large data set to test this hypothesis. Our data set is especially suitable for testing the relationship between inflation and the pass-through because it includes countries with pronounced differences in inflationary experience. We find strong evidence that the relation between the pass-through and the average inflation rate is positive and significant across regimes. This relation remains robust even when we control for other macroeconomic variables. These results are based on comparisons of regimes across countries as well as across periods.

An important policy implication of these findings is that the dependence of the exchange rate pass-through on the inflation regime should be taken into account in designing monetary policy rules. This dependency would make it easier for a country to implement a policy targeting for a low inflation rate. It should be emphasized, however, that the credibility of a low inflation regime would need to be established before the benefits of a low pass-through can be realized.

To focus on the influence of the inflationary environment on the exchange rate passthrough to CPI, this paper's estimates of the pass-through have been based on a model that abstracts from the role of microeconomic factors emphasized in the traditional literature. Exploring the relative importance of these factors in determining the pass-through to CPI (or to certain components of CPI) would be an interesting topic for future research. Our model assumes producer currency pricing and thus implies that the pass-through to import prices does not depend on the inflationary environment. One interesting extension of the paper's model would be to allow for the possibility that the choice between producer and local currency pricing depends on the inflationary environment. 
Table 1. Selected Characteristics of Inflation: Sample Countries

\begin{tabular}{|c|c|c|c|c|c|c|c|c|c|}
\hline Country & $\begin{array}{l}\text { Mean Annual } \\
\text { Inflation }\end{array}$ & $\begin{array}{l}\text { Maximum } \\
\text { (in percent }\end{array}$ & Minimum & Std. Dev. & Country & $\begin{array}{c}\text { Mean Annual } \\
\text { Inflation }\end{array}$ & $\begin{array}{l}\text { Maximum } \\
\text { (in percent) }\end{array}$ & Minimum & Std. Dev. \\
\hline Industrial Countries & & & & & & & & & \\
\hline Austria & 3.0 & 9.7 & -0.9 & 2.0 & Ghana & 29.7 & 162.5 & -62.7 & 28.1 \\
\hline Australia & 5.3 & 13.3 & -1.2 & 3.7 & Greece & 13.5 & 28.8 & 1.3 & 6.7 \\
\hline Belgium & 3.4 & 10.7 & -0.8 & 2.6 & Guatemala & 11.9 & 53.6 & -10.7 & 12.2 \\
\hline Canada & 4.2 & 12.9 & -2.7 & 3.3 & Haiti & 13.0 & 61.5 & -55.4 & 13.8 \\
\hline Denmark & 4.4 & 19.4 & 0.2 & 3.6 & Honduras & 12.3 & 41.2 & 1.5 & 8.8 \\
\hline Finland & 4.5 & 14.3 & -0.9 & 3.5 & Hungary & 13.9 & 38.5 & -1.8 & 8.5 \\
\hline France & 4.4 & 15.5 & -0.3 & 4.0 & Indonesia & 10.9 & 75.0 & -10.7 & 12.6 \\
\hline Germany & 2.6 & 8.6 & -6.3 & 2.3 & India & 7.9 & 23.7 & -1.9 & 5.3 \\
\hline Ireland & 5.6 & 23.0 & -0.3 & 5.5 & Israel & 39.2 & 199.6 & -5.7 & 48.1 \\
\hline Italy & 7.2 & 22.7 & 0.8 & 5.3 & Jamaica & 18.1 & 77.2 & 1.5 & 15.2 \\
\hline Netherlands & 2.7 & 7.8 & -3.7 & 2.1 & Jordan & 5.5 & 38.0 & -8.6 & 8.3 \\
\hline Norway & 5.1 & 13.8 & -1.7 & 3.6 & Kenya & 12.6 & 57.3 & -6.2 & 10.8 \\
\hline New Zealand & 6.6 & 28.7 & -2.0 & 6.1 & Korea & 6.7 & 35.1 & -2.9 & 6.9 \\
\hline Singapore & 2.3 & 14.7 & -3.6 & 3.1 & Madagascar & 15.6 & 62.1 & -3.0 & 13.5 \\
\hline Spain & 6.9 & 17.0 & 0.5 & 4.2 & Malaysia & 3.6 & 11.4 & -1.7 & 2.6 \\
\hline Sweden & 5.2 & 16.4 & -2.6 & 4.4 & Mexico & 32.3 & 117.0 & 2.3 & 25.7 \\
\hline Switzerland & 2.7 & 10.7 & -1.7 & 2.5 & Morocco & 5.6 & 20.6 & -2.2 & 4.7 \\
\hline UK & 5.4 & 28.8 & -0.9 & 4.5 & Nepal & 9.1 & 28.8 & -4.0 & 6.5 \\
\hline USA & 4.2 & 15.0 & -1.6 & 3.1 & Nicaragua & 113.1 & 759.8 & -11.3 & 182.9 \\
\hline Developing Countries & & & & & Pakistan & 7.9 & 20.3 & -0.1 & 4.3 \\
\hline Argentina & 88.6 & 813.2 & -3.9 & 127.4 & Papua New Guinea & 8.1 & 28.1 & -2.0 & 6.5 \\
\hline Bahrain & 1.5 & 29.9 & -9.7 & 5.1 & Paraguay & 16.4 & 46.8 & -1.5 & 10.9 \\
\hline Bangladesh & 8.1 & 31.7 & -7.5 & 7.0 & Peru & 85.3 & 773.2 & -1.5 & 126.0 \\
\hline Bolivia & 60.1 & 679.6 & -0.5 & 123.5 & Philippines & 10.7 & 239.3 & -242.3 & 38.2 \\
\hline Brazil & 124.4 & 599.8 & -1.4 & 123.8 & Portugal & 10.7 & 33.9 & 1.2 & 7.9 \\
\hline Burundi & 10.2 & 42.3 & -20.2 & 12.2 & Romania & 35.1 & 166.6 & -14.5 & 46.7 \\
\hline Burkina Faso & 4.1 & 46.3 & -17.2 & 11.1 & South Africa & 11.2 & 23.2 & -0.6 & 4.4 \\
\hline Cameroon & 6.4 & 68.1 & -15.8 & 12.0 & Sierra Leone & 36.8 & 158.1 & -70.5 & 44.5 \\
\hline China & 5.9 & 35.1 & -6.8 & 7.8 & Thailand & 5.1 & 25.1 & -3.2 & 4.9 \\
\hline Chile & 14.7 & 46.1 & -1.0 & 9.8 & Trinidad & 8.4 & 24.4 & -1.1 & 5.4 \\
\hline Colombia & 19.8 & 31.3 & 3.8 & 5.8 & Tunisia & 6.3 & 16.7 & 1.0 & 3.4 \\
\hline Costa Rica & 18.4 & 80.2 & -3.0 & 14.2 & Turkey & 48.5 & 132.5 & 18.7 & 19.0 \\
\hline Ecuador & 32.1 & 98.4 & 7.3 & 17.3 & Uruguay & 39.1 & 89.6 & 2.9 & 22.1 \\
\hline Egypt & 11.8 & 42.9 & -7.2 & 9.4 & Venezuela & 27.6 & 121.4 & 2.7 & 20.6 \\
\hline EI Salvador & 12.7 & 31.8 & -4.8 & 8.5 & Zambia & 39.7 & 165.6 & -0.3 & 32.9 \\
\hline Ethiopia & 5.2 & 63.9 & -26.8 & 13.1 & Zimbabwe & 20.0 & 59.1 & -1.1 & 13.6 \\
\hline
\end{tabular}


Table 2. Estimates of Exchange Rate Pass-Through: Countries With A Single Inflation Regime

\begin{tabular}{|c|c|c|c|c|c|c|c|c|c|}
\hline \multirow[t]{2}{*}{ Country } & \multicolumn{4}{|c|}{ Exchange Rate Pass-Through For: } & \multirow[t]{2}{*}{ Country } & \multicolumn{4}{|c|}{ Exchange Rate Pass-Through For: } \\
\hline & $\mathrm{T}=1$ & $\mathrm{~T}=2$ & $\mathrm{~T}=4$ & $\mathrm{~T}=20$ & & $\mathrm{~T}=1$ & $\mathrm{~T}=2$ & $T=4$ & $\mathrm{~T}=20$ \\
\hline Low Inflation Countries & & & & & USA & 0.00 & -0.01 & 0.02 & 0.06 \\
\hline Austria & 0.04 & 0.05 & 0.05 & 0.05 & Average & 0.04 & 0.08 & 0.14 & 0.16 \\
\hline Australia & 0.03 & 0.06 & 0.10 & 0.14 & & & & & \\
\hline Bahrain & -0.08 & -0.09 & -0.09 & -0.09 & Moderate Inflation Count & & & & \\
\hline Bangladesh & 0.00 & 0.08 & 0.08 & 0.08 & Burundi & 0.12 & 0.10 & 0.09 & 0.09 \\
\hline Belgium & 0.08 & 0.10 & 0.19 & 0.26 & Chile & 0.17 & 0.18 & 0.35 & 0.38 \\
\hline Burkina Faso & 0.16 & 0.29 & 0.38 & 0.34 & Colombia & -0.01 & -0.01 & -0.01 & -0.01 \\
\hline Cameroon & 0.22 & 0.32 & 0.38 & 0.39 & Costa Rica & 0.03 & 0.14 & 0.57 & 0.57 \\
\hline Canada & 0.00 & 0.04 & 0.11 & 0.19 & Egypt & 0.01 & -0.01 & 0.21 & 0.24 \\
\hline China & 0.04 & 0.14 & 0.30 & 0.41 & El Salvador & 0.06 & 0.12 & 0.18 & 0.19 \\
\hline Denmark & 0.06 & 0.14 & 0.22 & 0.24 & Ghana & 0.14 & 0.12 & 0.20 & 0.09 \\
\hline Ethiopia & -0.01 & -0.06 & -0.09 & -0.10 & Greece & 0.12 & 0.25 & 0.42 & 0.48 \\
\hline Finland & -0.01 & 0.03 & -0.02 & -0.04 & Guatemala & 0.15 & 0.33 & 0.45 & 0.46 \\
\hline France & -0.01 & 0.03 & 0.11 & 0.18 & Haiti & 0.21 & 0.28 & 0.31 & 0.31 \\
\hline Germany & 0.05 & 0.11 & 0.13 & 0.13 & Honduras & 0.07 & 0.12 & 0.31 & 0.38 \\
\hline India & 0.06 & 0.09 & 0.10 & 0.10 & Hungary & 0.18 & 0.31 & 0.48 & 0.54 \\
\hline Ireland & 0.06 & 0.12 & 0.38 & 0.54 & Indonesia & 0.10 & 0.21 & 0.41 & 0.43 \\
\hline Italy & 0.04 & 0.06 & 0.11 & 0.18 & Jamaica & 0.17 & 0.33 & 0.49 & 0.53 \\
\hline Jordan & 0.13 & 0.27 & 0.44 & 0.40 & Kenya & 0.09 & 0.22 & 0.35 & 0.38 \\
\hline Korea & 0.06 & 0.08 & 0.10 & 0.12 & Madagascar & 0.01 & 0.21 & 0.31 & 0.32 \\
\hline Malaysia & -0.01 & 0.03 & 0.05 & 0.05 & Paraguay & 0.07 & 0.19 & 0.34 & 0.34 \\
\hline Morocco & 0.10 & 0.26 & 0.29 & 0.29 & Philippines & 0.00 & 0.33 & 0.35 & 0.35 \\
\hline Nepal & 0.12 & 0.25 & 0.31 & 0.31 & Portugal & -0.01 & 0.08 & 0.44 & 0.54 \\
\hline Netherlands & 0.05 & 0.10 & 0.19 & 0.23 & South Africa & 0.02 & 0.07 & 0.13 & 0.14 \\
\hline Norway & 0.01 & 0.07 & 0.08 & 0.13 & Venezuela & 0.29 & 0.36 & 0.50 & 0.61 \\
\hline New Zealand & 0.05 & 0.13 & 0.27 & 0.42 & Zimbabwe & 0.06 & 0.17 & 0.29 & 0.32 \\
\hline Pakistan & -0.05 & -0.06 & -0.07 & -0.07 & Average & 0.09 & 0.19 & 0.33 & 0.35 \\
\hline Papua New Guinea & 0.11 & 0.23 & 0.36 & 0.38 & & & & & \\
\hline Singapore & -0.08 & -0.13 & -0.13 & -0.13 & High Inflation Countries & & & & \\
\hline Spain & 0.00 & 0.03 & 0.11 & 0.15 & Ecuador & 0.13 & 0.34 & 0.60 & 0.68 \\
\hline Sweden & 0.02 & 0.03 & 0.03 & 0.03 & Sierra Leone & 0.27 & 0.29 & 0.52 & 0.52 \\
\hline Switzerland & 0.08 & 0.07 & 0.07 & 0.07 & Turkey & 0.36 & 0.46 & 0.51 & 0.52 \\
\hline Thailand & 0.02 & 0.07 & 0.14 & 0.19 & Uruguay & 0.19 & 0.27 & 0.45 & 0.62 \\
\hline Trinidad & 0.04 & 0.08 & 0.12 & 0.13 & Zambia & 0.15 & 0.27 & 0.41 & 0.46 \\
\hline Tunisia & -0.03 & 0.05 & 0.09 & 0.10 & Average & 0.22 & 0.32 & 0.50 & 0.56 \\
\hline UK & -0.01 & -0.01 & 0.02 & 0.03 & & & & & \\
\hline
\end{tabular}


Table 3. Estimates of Exchange Rate Pass-Through: Countries With Two Inflation Regimes

\begin{tabular}{|c|c|c|c|c|c|c|}
\hline \multirow[t]{2}{*}{ Country } & \multicolumn{3}{|c|}{ Exchange Rate Pass Through For: } & \multirow[b]{2}{*}{$T=20$} & \multirow[t]{2}{*}{ F-test } & \\
\hline & $\mathrm{T}=1$ & $\mathrm{~T}=2$ & $T=4$ & & & \\
\hline \multicolumn{7}{|l|}{ Argentina } \\
\hline Moderate Inflation (1991:3-2000:4) & 0.01 & 0.06 & -0.09 & -0.09 & & \\
\hline High Inflation (1980:1-1991:2) & 0.67 & 1.02 & 1.01 & 1.09 & 17.02 & * \\
\hline High Inflation (1980:2-1989:1) & 0.62 & 0.68 & 0.76 & 0.79 & 25.95 & * \\
\hline \multicolumn{7}{|l|}{ Brazil } \\
\hline Moderate Inflation (1994:4-2000:4) & 0.08 & 0.17 & 0.39 & 0.44 & & \\
\hline High Inflation (1981:1-1994:3) & 0.75 & 0.33 & 0.63 & 0.63 & 95.75 & * \\
\hline High Inflation (1980:2-1989:2) & 0.64 & 0.76 & 0.89 & 0.92 & 26.35 & * \\
\hline \multicolumn{7}{|l|}{ Israel } \\
\hline Moderate Inflation (1985:4-2000:4) & 0.25 & 0.28 & 0.28 & 0.28 & & \\
\hline High Inflation (1979:3-1985:3) & 0.64 & 0.83 & 0.83 & 0.83 & 47.87 & * \\
\hline \multicolumn{7}{|l|}{ Mexico } \\
\hline Moderate Inflation (1988:3-2000:4) & 0.09 & 0.27 & 0.27 & 0.27 & & \\
\hline High Inflation (1980:2-1988:2) & 0.25 & 0.28 & 0.28 & 0.28 & 17.87 & * \\
\hline \multicolumn{7}{|l|}{ Peru } \\
\hline Moderate Inflation (1993:3-2000:4) & -0.11 & -0.07 & -0.20 & -0.20 & & \\
\hline High Inflation (1980:2-1993:2) & 0.49 & 0.64 & 0.64 & 0.64 & 16.83 & * \\
\hline High Inflation (1980:3-1988:2) & 0.06 & 0.29 & 0.52 & 0.40 & 4.32 & * \\
\hline \multicolumn{7}{|l|}{ Romania } \\
\hline Moderate Inflation (1981:3-1990:3) & 0.06 & -0.01 & 0.03 & 0.06 & & \\
\hline High Inflation (1990:4-2000:4) & 0.30 & 0.47 & 0.47 & 0.47 & 5.45 & * \\
\hline \multicolumn{6}{|l|}{ Bolivia } & \\
\hline Moderate Inflation (1986:2-2000:4) & 0.02 & 0.08 & 0.09 & 0.09 & NA & \\
\hline \multicolumn{7}{|l|}{ Nicaragua } \\
\hline Moderate Inflation (1991:3-2000:4) & 0.46 & 0.28 & 0.28 & 0.28 & NA & \\
\hline
\end{tabular}

Notes: The $\mathrm{F}$ test tests the null hypothesis that the coefficients on the nominal exchange rates, the lagged consumer prices, and the

foreign prices are equal in the indicated high and moderate inflation regimes. ${ }^{*}$ indicates significance at the 5 percent level. 
Table 4. Correlation of Exchange Rate Pass-Through With the Average Inflation Rate: Regressions in First Differences

\begin{tabular}{|c|c|c|c|c|c|c|c|c|c|}
\hline \multirow[t]{2}{*}{ Sample } & \multirow{2}{*}{$\begin{array}{c}\text { No. of } \\
\text { observations }\end{array}$} & \multicolumn{4}{|c|}{ Pearson Correlations } & \multicolumn{4}{|c|}{ Spearman Correlations } \\
\hline & & $\mathrm{T}=1$ & $\mathrm{~T}=2$ & $\mathrm{~T}=4$ & $\mathrm{~T}=20$ & $\mathrm{~T}=1$ & $\mathrm{~T}=2$ & $\mathrm{~T}=4$ & $\mathrm{~T}=20$ \\
\hline \multicolumn{10}{|l|}{ All country sample } \\
\hline All observations & 77 & 0.86 & 0.74 & 0.66 & 0.62 & 0.60 & 0.67 & 0.69 & 0.65 \\
\hline Observations including only developing countries & 58 & 0.85 & 0.72 & 0.65 & 0.62 & 0.60 & 0.61 & 0.65 & 0.63 \\
\hline \multicolumn{10}{|l|}{ Country sample with one inflation regime } \\
\hline All observations & 63 & 0.66 & 0.58 & 0.60 & 0.56 & 0.50 & 0.58 & 0.64 & 0.59 \\
\hline Observations including only developing countries & 44 & 0.62 & 0.50 & 0.52 & 0.52 & 0.47 & 0.46 & 0.57 & 0.54 \\
\hline Country sample with two inflation regimes & 14 & 0.87 & 0.77 & 0.84 & 0.83 & 0.87 & 0.88 & 0.84 & 0.84 \\
\hline
\end{tabular}

Notes: All correlations are significant at the $5 \%$ level using a one-tailed test of positive correlation. Tests of significance

for the Spearman correlations are based on quantiles of Spearman's rho in Conover (1999). 
Table 5. Correlation of Exchange Rate Pass-Through With the Average Inflation Rate: Additional Regressions

\begin{tabular}{|c|c|c|c|c|c|c|c|c|c|}
\hline & \multirow{2}{*}{$\begin{array}{c}\text { No. of } \\
\text { observations }\end{array}$} & \multicolumn{4}{|c|}{ Pearson Correlations } & \multicolumn{4}{|c|}{ Spearman Correlations } \\
\hline & & $T=1$ & $\mathrm{~T}=2$ & $T=4$ & $\mathrm{~T}=20$ & $\mathrm{~T}=1$ & $\mathrm{~T}=2$ & $\mathrm{~T}=4$ & $\mathrm{~T}=20$ \\
\hline \multicolumn{10}{|l|}{ Regressions in Levels } \\
\hline All country sample & 77 & 0.81 & 0.77 & 0.58 & 0.31 & 0.61 & 0.71 & 0.73 & 0.64 \\
\hline Country sample with one inflation regime & 63 & 0.61 & 0.63 & 0.60 & 0.41 & 0.54 & 0.64 & 0.68 & 0.57 \\
\hline Country sample with two inflation regimes & 14 & 0.78 & 0.71 & 0.47 & $0.24^{\mathrm{a}}$ & 0.82 & 0.89 & 0.87 & 0.72 \\
\hline \multicolumn{10}{|c|}{ Regressions in First Differences With Money Growth } \\
\hline All country sample & 75 & 0.85 & 0.84 & 0.72 & 0.70 & 0.58 & 0.66 & 0.64 & 0.65 \\
\hline Country sample with one inflation regime & 61 & 0.56 & 0.48 & 0.45 & 0.45 & 0.48 & 0.55 & 0.53 & 0.53 \\
\hline Country sample with two inflation regimes & 14 & 0.88 & 0.96 & 0.89 & 0.91 & 0.86 & 0.94 & 0.93 & 0.89 \\
\hline
\end{tabular}


Table 6. Regression Estimates: Total Sample

\begin{tabular}{|c|c|c|c|c|c|c|c|c|c|c|}
\hline \multirow[b]{3}{*}{ Constant } & \multicolumn{10}{|c|}{ Dependent Variable } \\
\hline & \multicolumn{5}{|c|}{ Exchange Rate Pass Through at $\mathrm{T}=1$} & \multicolumn{5}{|c|}{ Exchange Rate Pass Through at $\mathrm{T}=20$} \\
\hline & $\begin{array}{l}0.025 * \\
(0.01)\end{array}$ & $\begin{array}{l}0.082 * \\
(0.01)\end{array}$ & $\begin{array}{l}0.071 * \\
(0.01)\end{array}$ & $\begin{array}{l}0.145 * \\
(0.03)\end{array}$ & $\begin{array}{r}0.014 \\
(0.02)\end{array}$ & $\begin{array}{l}0.188 * \\
(0.02)\end{array}$ & $\begin{array}{l}0.249 * \\
(0.02)\end{array}$ & $\begin{array}{c}0.236 * \\
(0.03)\end{array}$ & $\begin{array}{l}0.325 * \\
(0.05)\end{array}$ & $\begin{array}{l}0.177 * \\
(0.04)\end{array}$ \\
\hline Inflation & $\begin{array}{l}0.439 * \\
(0.03)\end{array}$ & & & & $\begin{array}{l}0.528 * \\
(0.06)\end{array}$ & $\begin{array}{l}0.470 * \\
(0.07)\end{array}$ & & & & $\begin{array}{l}0.584 * \\
(0.13)\end{array}$ \\
\hline Inflation Variance & & $\begin{array}{l}0.314 * \\
(0.04)\end{array}$ & & & $\begin{array}{r}-0.094 \\
(0.10)\end{array}$ & & $\begin{array}{l}0.325 * \\
(0.07)\end{array}$ & & & $\begin{array}{r}-0.279 \\
(0.23)\end{array}$ \\
\hline Exchange Rate Variance & & & $\begin{array}{l}0.243 * \\
(0.03)\end{array}$ & & $\begin{array}{r}-0.001 \\
(0.08)\end{array}$ & & & $\begin{array}{l}0.263 * \\
(0.05)\end{array}$ & & $\begin{array}{l}0.122 \\
(0.17)\end{array}$ \\
\hline Import to GDP Ratio & & & & $\begin{array}{r}-0.001 \\
(0.001)\end{array}$ & $\begin{array}{r}0.0001 \\
(0.0004)\end{array}$ & & & & $\begin{array}{r}-0.001 \\
(0.001)\end{array}$ & $\begin{array}{r}0.000 \\
(0.001)\end{array}$ \\
\hline Adjusted R-sqaured & 0.73 & 0.54 & 0.43 & 0.01 & 0.73 & 0.38 & 0.21 & 0.23 & 0.01 & 0.37 \\
\hline
\end{tabular}

* indicates significance at the 5 percent level. 
Table 7. Regression Estimates: Selected Samples

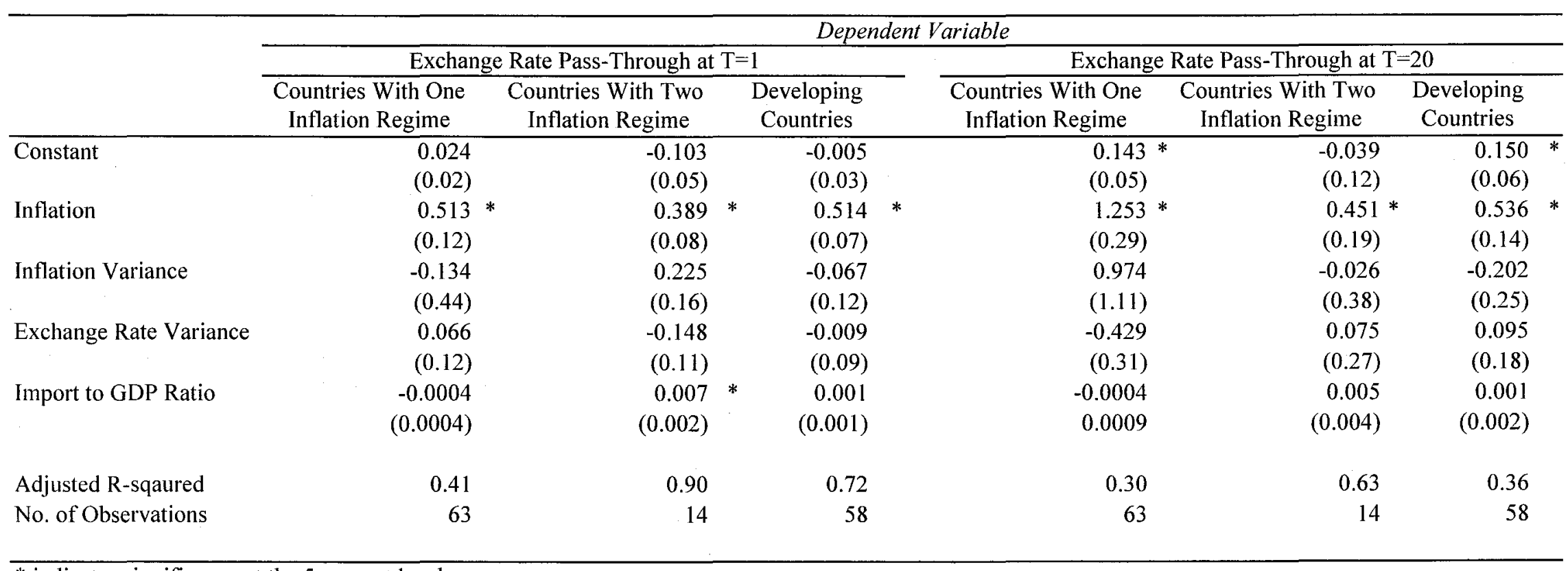

* indicates significance at the 5 percent level. 
Table 8. Regression Estimates: Weighted Least Sqaures

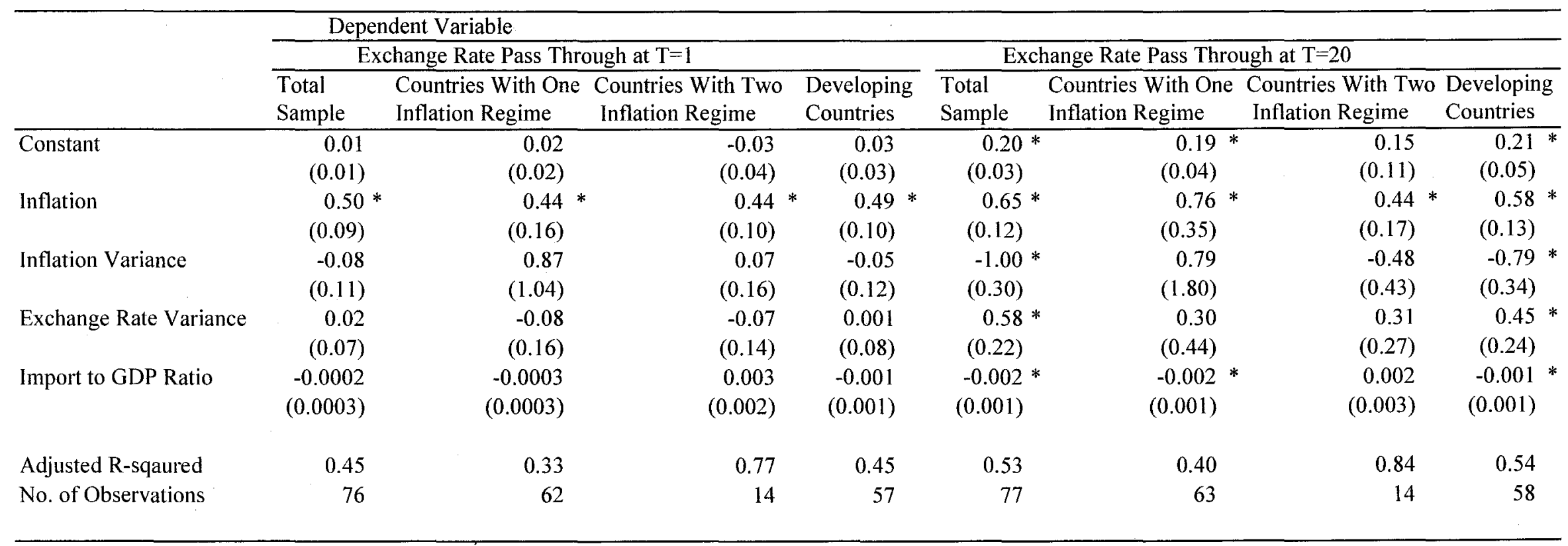

* indicates significance at the 5 percent level.

Note: The regression results for the $T=1$ pass-through exclude Burkina Faso (see text for explanation). 
Figure 1. Countries With Shifts in Inflation Regimes
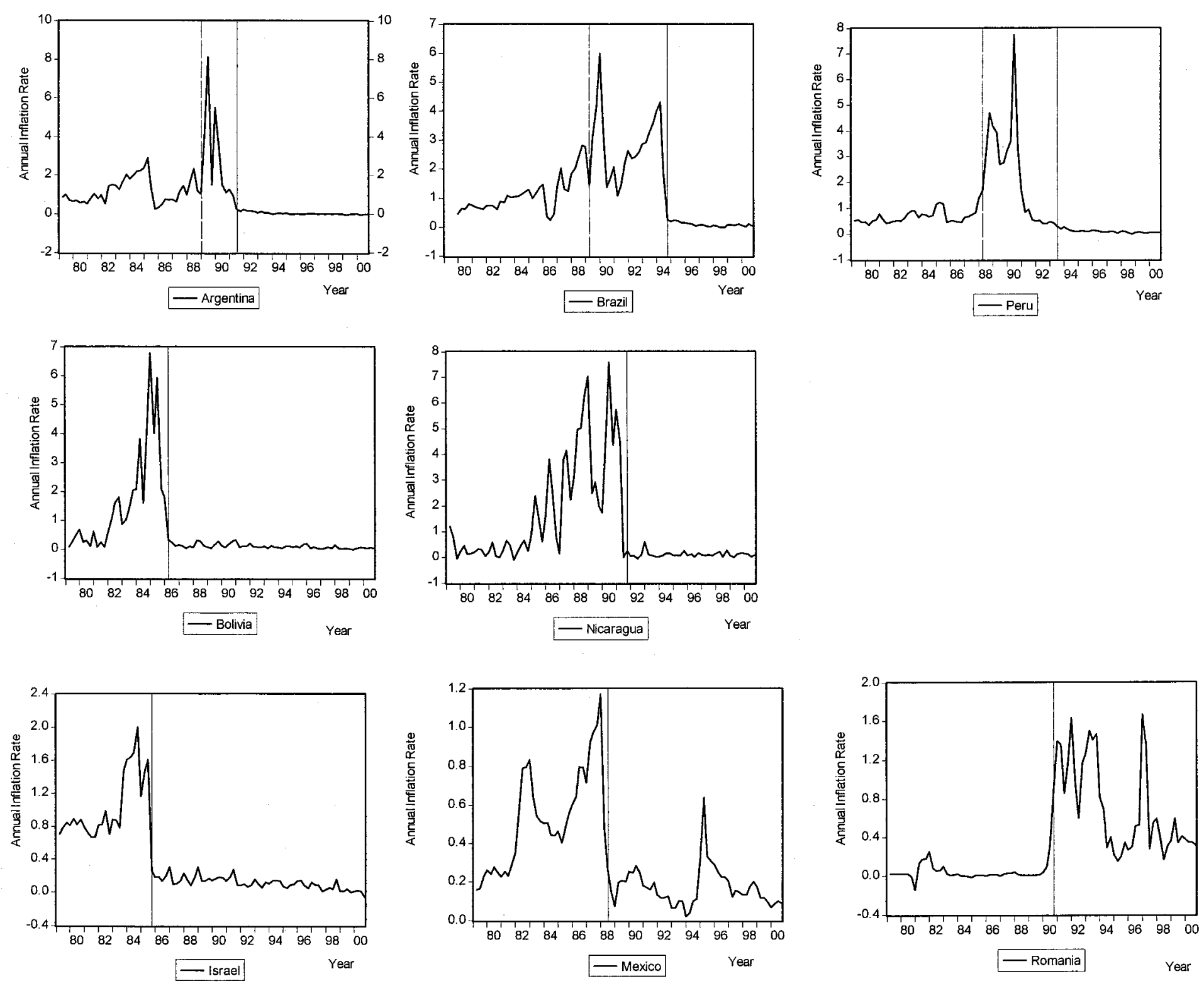
Figure 2. Association Between Average Inflation and Exchange Rate Pass-Through

a.

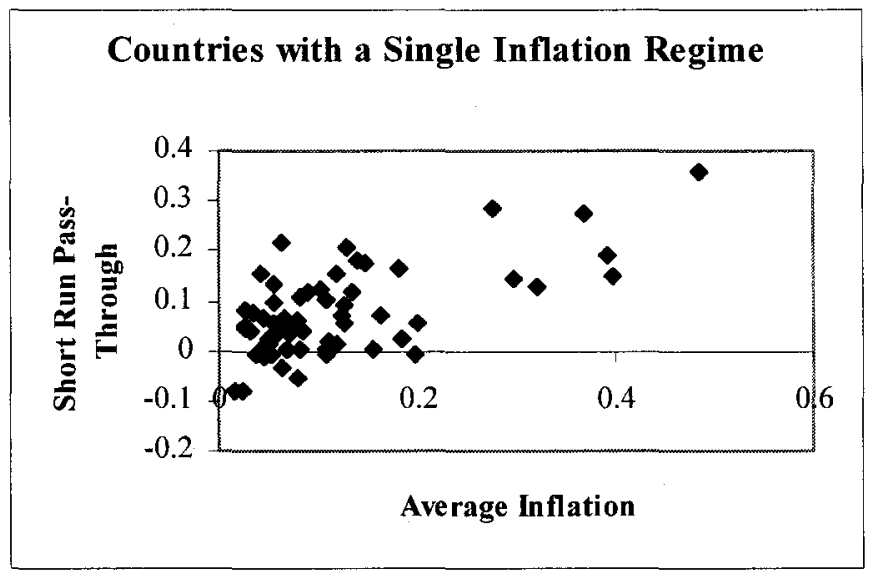

c.

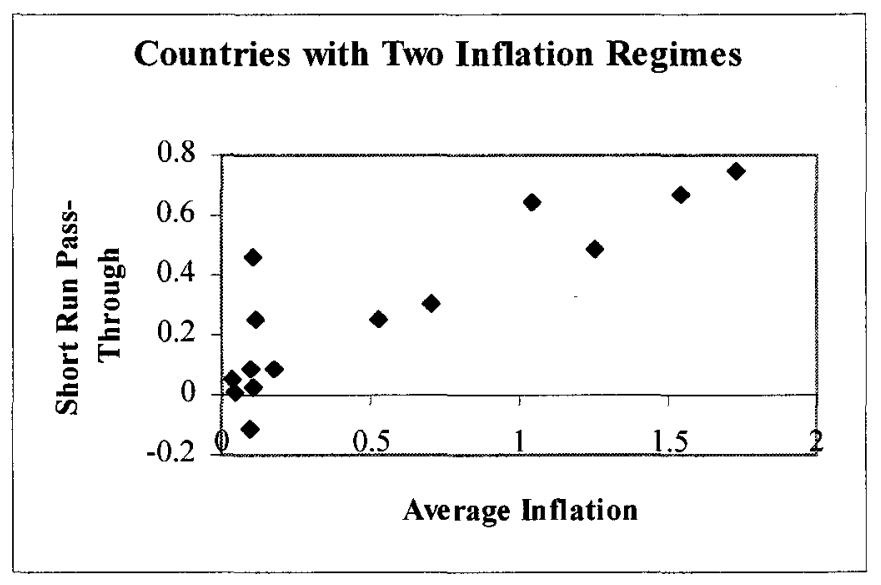

b.

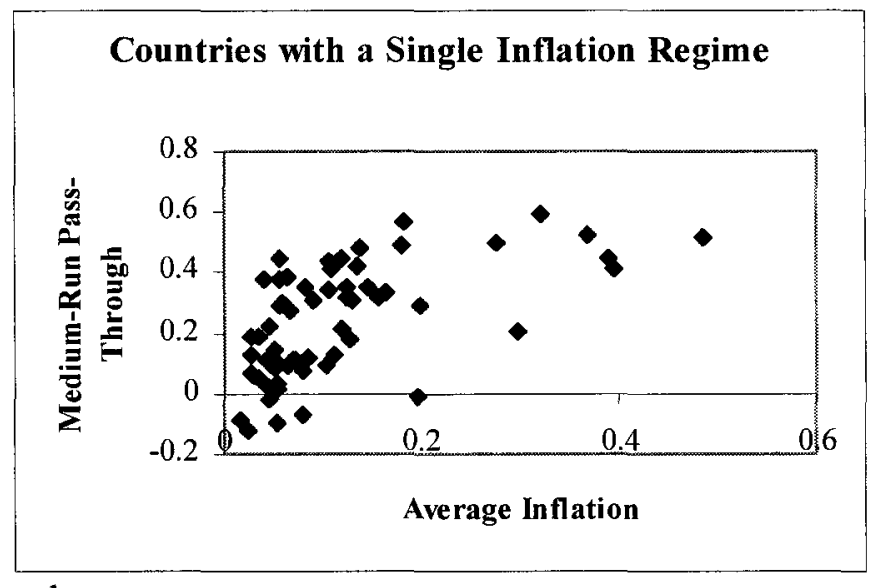

d.

\section{Countries with Two Inflation Regimes}

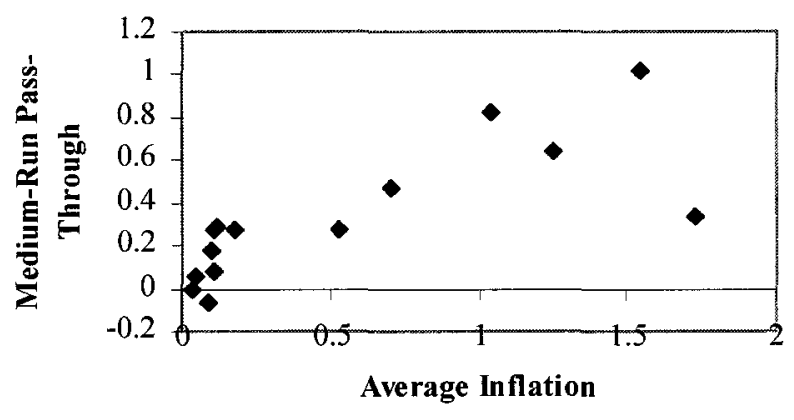




\section{APPENDIX I}

\section{A. Complete Asset Markets}

Letting $T=2$, use (9)-(11), (15) and the assumption that $p_{t}^{*}=0$ to obtain

$$
x_{t}=\kappa\left(x_{t-1}+E_{t}^{x} x_{t+1}\right)+\omega\left(s_{t}+E_{t}^{x} s_{t+1}\right)
$$

where $\kappa=\alpha \theta /(2(2-\alpha \theta))$ and $\omega=(1-\alpha \theta) /(2-\alpha \theta)$. Next use (14), (15) and the assumption that $v_{t}$ is white noise to express (A1) as

$$
x_{t}=\left[(\kappa-\rho \omega) x_{t-1}+\kappa E_{i}^{x} x_{t+1}+\omega v_{t}\right] /(1+\rho \omega)
$$

Assume a solution of the form

$$
x_{t}=\phi_{1} x_{t-1}+\phi_{2} v_{t}
$$

After solving the model to determine $\phi_{1}$ and $\phi_{2}$, we use (14) and (15) to express (A3) as $x_{t}=\left(\phi_{1}+\rho \phi_{2}\right) x_{t-1}+\phi_{2} s_{t}$, and then use (10) to derive (16) with $\mu_{1} \equiv \phi_{1}+\rho \phi_{2}$ and $\mu_{2} \equiv \phi_{2}$. Using (A3) to determine $E_{t}^{x} x_{t+1}$, write (A2) as

$$
x_{t}=\left[\left(\kappa-\rho \omega+\kappa \phi_{1}^{2}\right) x_{t-1}+\left(\kappa \phi_{1} \phi_{2}+\omega\right) v_{t}\right] /(1+\rho \omega)
$$

Matching coefficients between (A3) and (A4), the coefficients in (A3) are given by

$$
\begin{gathered}
\kappa \phi_{1}^{2}-(1+\rho \omega) \phi_{1}+(\kappa-\rho \omega)=0, \\
\phi_{2}=\omega /\left(1+\rho \omega-\kappa \phi_{1}\right) .
\end{gathered}
$$

Solving (A5) and (A6) numerically (and using the stable root of the quadratic equation (A5), i.e., $\left.\left|\phi_{1}\right|<1\right)$, we determine that $\phi_{1}$ as well as $\phi_{2}$ decrease in $\rho$ and thus both $\mu_{1}$ and $\mu_{2}$ decrease in $\rho$, given that $\alpha \theta$ is in the $(0,1)$ interval (note that both $\kappa$ and $\omega$ depend on $\alpha \theta$ ). This correspondence is illustrated in the Appendix Table for selected values of $\rho$ and $\alpha \theta$.

\section{B. Incomplete Asset Markets}

Now use (9)-(11), (18) and the assumptions that $p_{t}^{*}=0$ and $\eta_{t}$ is white noise to obtain

$$
x_{t}=\kappa\left(x_{t-1}+E_{t}^{x} x_{t+1}\right)+\omega\left(s_{t}+E_{t}^{x} s_{t+1}\right)-\psi \eta_{t}
$$

where $\psi=(1-\alpha) /(2-\alpha \theta)$. Then use (14) and (18) to express (A7) as 


$$
x_{t}=\left[(\kappa-\rho \omega) x_{t-1}+\kappa E_{t}^{x} x_{t+1}+\omega\left(v_{t}+\eta_{t}\right)-\psi E_{t}^{x} \eta_{t}\right] /(1+\rho \omega) .
$$

Assume a solution of the form

$$
x_{t}=\widetilde{\phi}_{1} x_{t-1}+\widetilde{\phi}_{2}\left(v_{t}+\eta_{t}\right)
$$

Since $s_{t}=v_{t}+\eta_{t}-\rho x_{t-1}$ from (14) and (18), (A9) and (10) can be used to derive (16) with $\mu_{1} \equiv \widetilde{\phi}_{1}+\rho \widetilde{\phi}_{2}$ and $\mu_{2} \equiv \widetilde{\phi}_{2}$. Also note that firms observe $s_{t}$ in period $t$ and thus know $v_{t}+\eta_{t}$. They do not know $\eta_{t}$ but can derive its expected value as $E_{t}^{x} \eta_{t}=\lambda\left(v_{t}+\eta_{t}\right)$ with $\lambda=\sigma_{\eta}^{2} /\left(\sigma_{\eta}^{2}+\sigma_{v}^{2}\right)$. Using this expression, and (A9) to determine $E_{t}^{x} x_{t+1}$, express (A8) as

$$
x_{t}=\left[\left(\kappa-\rho \omega+\kappa \widetilde{\phi}_{1}^{2}\right) x_{t-1}+\left(\kappa \widetilde{\phi}_{1} \widetilde{\phi}_{2}+\omega-\psi \lambda\right)\left(v_{t}+\eta_{t}\right] /(1+\rho \omega) .\right.
$$

Using (A9) and (A10) to determine $\widetilde{\phi}_{1}$ and $\widetilde{\phi}_{2}$, it can be shown that the coefficient of $x_{t-1}$ in (A9) is the same as before, i.e., $\widetilde{\phi}_{1}=\phi_{1}$. The coefficient of $v_{t}+\eta_{t}$, however, equals $\widetilde{\phi}_{2}=(\omega-\psi \lambda) /\left(1+\rho \omega-\kappa \widetilde{\phi}_{1}\right)$. Thus $\mu_{2}\left(\equiv \widetilde{\phi}_{2}\right)$ decreases in $\lambda$ and can be shown to decrease in $\rho$ as well.

For $T=2$, use (10) and (A9) to obtain the variance of $p$ as

$$
\operatorname{var}(p)=\widetilde{\phi}_{2}^{2}\left(\sigma_{\eta}^{2}+\sigma_{v}^{2}\right) / 2\left(1-\widetilde{\phi}_{1}^{2}\right) .
$$

As (A11) indicates, $\operatorname{var}(p)$ decreases in $\rho$ since both $\widetilde{\phi}_{1}$ and $\widetilde{\phi}_{2}$ decrease in $\rho$. Note that $\widetilde{\phi}_{2}$ decreases in $\sigma_{\eta}^{2}$, and increases in $\sigma_{v}^{2}$. Thus $\operatorname{var}(p)$ increases in $\sigma_{v}^{2}$, but the sign of the partial effect of $\sigma_{\eta}^{2}$ on $\operatorname{var}(p)$ is ambiguous. Next, use (14), (18) and (A9) to obtain the variance of $s$ as

$$
\operatorname{var}(s)=\left(\sigma_{\eta}^{2}+\sigma_{v}^{2}\right)\left[1+\left(\rho^{2} \widetilde{\phi}_{2}^{2}\right) /\left(1-\widetilde{\phi}_{1}^{2}\right)\right]
$$

According to (A12), $\operatorname{var}(s)$ increases in $\sigma_{v}^{2}$, but the signs of the partial effects of both $\rho$ and $\sigma_{\eta}^{2}$ on $\operatorname{var}(s)$ are ambiguous. 
Appendix Table

\begin{tabular}{llll}
\hline Coefficients & $\rho$ & $\mu_{1}$ & $\mu_{2}$ \\
\hline & & & \\
$\alpha \theta=0.1$ & 0.1 & 0.025 & 0.451 \\
& 0.3 & 0.023 & 0.413 \\
& 0.5 & 0.021 & 0.382 \\
& 0.7 & 0.020 & 0.354 \\
& 0.9 & 0.018 & 0.330 \\
$\alpha \theta=0.5$ & & & \\
& 0.1 & 0.165 & 0.330 \\
& 0.3 & 0.153 & 0.306 \\
& 0.5 & 0.143 & 0.286 \\
& 0.7 & 0.134 & 0.268 \\
$\alpha \theta=0.9$ & 0.9 & 0.127 & 0.253 \\
& & & \\
& 0.1 & 0.508 & 0.113 \\
& 0.3 & 0.486 & 0.108 \\
& 0.5 & 0.467 & 0.104 \\
& 0.7 & 0.451 & 0.100 \\
& 0.9 & 0.436 & 0.097 \\
\hline
\end{tabular}




\section{REFERENCES}

Basu, Susanto, 1995, "Intermediate Goods And Business Cycles: Implications For Productivity And Welfare," American Economic Review, Vol. 85, pp. 512-531.

Bergin, Paul, and Robert Feenstra, 2001, "Pricing-To-Market, Staggered Contracts, And Real Exchange Rate Persistence," Journal of International Economics, Vol. 54, pp. 333-359.

Calvo, Guillermo, and Carmen Reinhart, 2000, "Fixing for your Life," National Bureau of Economic Research Working Paper No. 8006 (Massachusetts: NBER).

Campa, Jose, and Linda Goldberg, 2001, "Exchange Rate Pass-Through Into Import Prices: A Macro or Micro Phenomenon?" mimeo, Federal Reserve Bank of New York.

Chiang, Min-Hsien, and Chihwa Kao, 2001, "Nonstationary Panel Time Series Using NPT 1.2 - A User Guide," mimeo, Center for Policy Research, Syracuse University.

Conover, W. J., 1999, Practical Nonparametric Statistics, (New York: John Wiley and Sons, Inc., $3^{\text {rd }}$ ed.).

Devereux, Michael, and Charles Engel, 2001, "Endogenous Currency of Price Setting in a Dynamic Open Economy Model," mimeo.

Gagnon, Joseph, and Jane Ihrig, 2001, "Monetary Policy And Exchange Rate Pass-Through," Board of Governors of the Federal Reserve System International Finance Discussion Paper No. 704.

Goldberg, Pinelopi, and Michael Knetter, 1997, "Goods Prices and Exchange Rates: What Have We Learned?" Journal of Economic Literature, Vol. 35, pp. 1243-92.

Goldfajn, Ilan, and Sergio Werlang, 2000, "The Pass-Through From Depreciation To Inflation: A Panel Study" Departamento De Economia Puc-Rio Texto Para Discussao No. 424.

Im, Kyung So, Hashem Pesaran, and Yongcheol Shin, 1997, “Testing for Unit Roots in Heterogeneous Panels," Discussion Paper, University of Cambridge, December.

Lane, Philip, and Gian Maria Milesi-Ferretti, 2000, "The Transfer Problem Revisited: Net Foreign Assets and Real Exchange Rates," IMF Working Paper 00/123 (Washington: International Monetary Fund).

Levin, Andrew, and Chien-Fu Lin, 1993, "Unit Root Tests in Panel Data: Asymptotic and Finite-Sample Properties," Discussion Paper 93-56, University of California, San Diego.

McCallum, Bennett, and Edward Nelson, 1999, "Nominal Income Targeting in an OpenEconomy Optimizing Model," Journal of Monetary Economics, Vol. 43, pp. 553-578. 
McCarthy, Jonathan, 2000, "Pass-Through of Exchange Rates and Import Prices to Domestic Inflation in Some Industrialized Economies," mimeo, Federal Reserve Bank of New York.

Taylor, Alan, 2000, "A Century of Purchasing-Power Parity," National Bureau of Economic Research Working Paper No. 8012 (Massachusetts: NBER).

Taylor, John, 2000, "Low Inflation, Pass-Through, and the Pricing Power of Firms," European Economic Review, Vol. 44, pp. 1389-1408.

Zanello, Alessandro and Dominique Desruelle, 1997, "A Primer on the IMF's Information Notice System,” IMF Working Paper 97/71 (Washington: International Monetary Fund). 